\title{
ARTÍCULO
}

\section{Proyectos de ingeniería y conflicto armado: Una perspectiva de RSE}

\author{
Villegas Rodríguez, Luis Carlos*, Delgado Gómez, Dora Luz ${ }^{\circ}$ \\ * Universidad de Medellín \\ lcvillegas@udem.edu.co \\ ○ Universidad de Medellín \\ ddelgado@udem.edu.co
}

El presente artículo tiene como objetivo analizar la actuación de empresas que construyen y operan obras de ingeniería en relación con el conflicto armado en Colombia, en particular desde finales del siglo pasado. A medida que el conflicto se intensificó, las empresas se vieron desbordadas por la gravedad de la amenaza y asumieron diferentes posturas frente a ello: simpatía, subordinación, seguridad y resistencia. Este trabajo hace énfasis en la postura de resistencia, asociada a aquellas empresas que se niegan a respaldar a los grupos armados ilegales; que, además, realizan procesos de reflexión, en ocasiones colectivos, sobre el conflicto y que deciden aportar a su solución a largo plazo. Estas empresas, en conjunto con otros actores regionales, como las iglesias, las organizaciones sociales y comunidades en general, participaron en la construcción de Programas de Desarrollo y Paz (PDP), los cuales plantearon como objetivo fundamental servir de facilitadores para empoderar a las comunidades sobre su territorio y así lograr la mejora de la calidad de vida y disminuir las violaciones a los derechos humanos. Por ello, estos programas se constituyeron, tanto para las obras como para los pobladores de estos territorios, en los principales facilitadores de esa postura de resistencia frente a las amenazas de grupos armados al margen de la ley. El análisis, realizado con enfoque cualitativo, concluye acerca de la propuesta de ciudadanía corporativa como estrategia de responsabilidad social empresarial (RSE), coherente con la actuación de las empresas que asumieron el enfoque de resistencia en los territorios en los cuales tienen sus obras. Se concluye, además, que dicha propuesta de RSE permite líneas de acción para las empresas hacia el futuro. Esto es todo un proceso de reconocimiento de las obras, más que como obras de ingeniería, como sistemas sociales, complejos, al tiempo que, igualmente, se reconoce la relación con los territorios, como una relación compleja a la cual convergen disciplinas y conocimientos, más allá de la ingeniería, pero en la cual la ingeniería tiene un rol significativo

\section{Palabras clave:}

Conflicto, empresa, territorio, ciudadanía corporativa, desarrollo y paz, obras de ingeniería 
Villegas y Delgado

Proyectos de ingeniería y conflicto armado: Una perspectiva de RSE

\section{INTRODUCCIÓN}

El conflicto armado que ha sufrido Colombia a lo largo de varias décadas tiene expresiones particularmente violentas en algunos territorios, en donde se convierte en una amenaza cotidiana a la seguridad personal, a la infraestructura empresarial y, en general, al logro de los objetivos de prestación de servicios, construcción de infraestructura y entrega de bienes, en el caso empresarial. De ahí la necesidad de indagar sobre las relaciones entre empresa y sociedad en un momento histórico: la transición de una sociedad caracterizada por un conflicto armado de larga duración hacia una sociedad dedicada a construir y afianzar la paz y a llevar a cabo procesos de mejora en la calidad de vida, procesos que se habían complejizado y aplazado debido al conflicto mismo.

El análisis del conflicto y de la respuesta empresarial, desde los últimos años del siglo pasado hasta la actualidad, permite extraer aprendizajes que sirvan de referencia para las empresas. En este contexto, la noción de conflicto se asocia a la de "soberanía en vilo" (Uribe, 1998, p. 11), propuesta y desarrollada por la investigadora María Teresa Uribe, que concibe los estados de guerra en Colombia como una consecuencia del no reconocimiento de la autoridad estatal por parte de grupos armados que resisten a los intentos de dominación por parte de esta. Dichos grupos solo reconocen su propio poder, conforman circuitos de control y resisten, por la fuerza, a los intentos de sometimiento por parte del Estado central (Uribe, 1998, p. 18). En efecto, el conflicto es un permanente desconocimiento de la soberanía del Estado y una voluntad de controlar territorios determinados.

Los servicios fundamentales del Estado, como la seguridad y la justicia, se constituyen en el eje de la puesta en vilo de la soberanía debido a la existencia de un Estado débil, incapaz de imponer su control y de prestar servicios sobre todo el territorio. Como consecuencia de lo anterior, la fuerza de la confrontación da lugar a situaciones de guerra que desbordan los territorios inicialmente ocupados. De ahí la urgencia de llegar con los servicios del Estado como estrategia para solucionar la puesta en vilo de la soberanía por medio de un proceso de construcción de paz. Por lo mismo, las propuestas a implementar a partir de la desmovilización de grupos armados ilegales (GAI) solo se pueden lograr mediante procesos de fortalecimiento del Estado, de la construcción de ciudadanía y del diseño y puesta en marcha de mecanismos de participación política y dotación de factores productivos que permitan superar las agudas problemáticas de exclusión y de baja de calidad de vida de una parte importante de la población (López, 2016, p. 43).

Los resultados de la investigación permiten afirmar que la actuación empresarial frente a los riesgos derivados del conflicto se desarrolló en un horizonte conformado por distintas posturas relacionadas con la simpatía, subordinación, seguridad y resistencia, las cuales se definen tomando como base la respuesta de las empresas frente a los GAI y el rol que le asignan a la comunidad en dicho proceso. Los elementos señalados permiten establecer que las empresas se convierten en actores del conflicto en la medida en que este compromete lineamientos importantes de su gestión para afrontar los riesgos sobre su viabilidad.

En algunos casos, las empresas elaboran un marco de actuación que reconoce, así sea de manera implícita, la complejidad de los territorios y la necesidad de una actuación ética que aporte a la solución del conflicto como una apuesta a largo plazo. En este artículo dicho actuar se analiza, desde el punto de vista de criterios de responsabilidad social empresarial, como una respuesta que IJESJP, 2018, V6, n1 
tiene como eje central la decisión de apoyar la construcción de paz y de desarrollo en el contexto del conflicto, a través de la promoción y participación en Programas de Desarrollo y Paz (PDP). Estos programas son expresiones no violentas de la sociedad civil, que tienen como objetivo facilitar y dar soporte a los pobladores para que logren procesos de empoderamiento individual y colectivo (Trujillo, 2012, p. 28) relacionados con su calidad de vida y con los derechos violados por los actores de la guerra presentes en dichos territorios.

Los PDP son alianzas de la sociedad civil que incluyen empresas, iglesias y organizaciones de las comunidades; alianzas diversas que excepcionalmente han contado con la participación de las instancias locales del Estado. Estos programas se convirtieron en uno de los principales motores de la resistencia de los pobladores frente al conflicto armado en sus momentos más críticos.

En lo relativo a los criterios de responsabilidad social empresarial, el análisis se sustenta en la propuesta de ciudadanía corporativa, una de las grandes líneas estratégicas de las prácticas de RSE en Colombia y en el mundo. La ciudadanía corporativa implica que "la empresa reflexione sobre el modelo de sociedad en la que desea vivir, sobre su contribución a esa sociedad y sobre sus responsabilidades desde una perspectiva de cambio y mejora social" (Castelló \& Lozano, 2009, p. 24). Desde esta perspectiva, la ciudadanía corporativa es un intento por integrar en los objetivos empresariales la actuación sobre problemas que son de interés de toda la sociedad, con el fin de contribuir a su solución. Con ello, la empresa intenta también ganar legitimidad.

Este artículo explica los aspectos metodológicos de la aplicación de las estrategias de investigación, en particular la entrevista en profundidad y los grupos focales. Se incluyen, además, los hallazgos de la investigación y, finalmente, se plantean conclusiones sobre el tema analizado.

\section{ASPECTOS METODOLÓGICOS}

El trabajo se realiza con el enfoque de investigación cualitativa, sus resultados se construyen a partir de la indagación en historias de personas que han participado, tanto en procesos empresariales relacionados con las comunidades, como en los PDP. De igual manera, incluye las perspectivas desde las empresas y la academia para conformar un calidoscopio de miradas, visiones y testimonios, que reúne voces y percepciones contrastantes y complementarias en ocasiones.

Este es un proceso de interacción abierta y reflexiva que permite indagar en los recuerdos y en las posiciones entre los sujetos de la investigación y los investigadores. Son treinta entrevistas en profundidad que recogen el espectro mencionado. Las personas entrevistadas se seleccionaron cuidadosamente con el fin de recoger un panorama amplio y representativo de respuestas a las preguntas planteadas: directivos de empresas, ingenieros vinculados a las obras, especialistas de gestión social, dirigentes locales de los PDP, dirigentes nacionales vinculados a los PDP y académicos que han elaborado experiencias relacionadas. El resultado entreteje conceptos como conflicto, territorio, empoderamiento, desarrollo y paz y responsabilidad social empresarial. El equipo de investigación realizó un proceso que consistió en: formulación del planteamiento del problema, definición de las preguntas de investigación, revisión de la literatura existente, definición de categorías, elaboración de análisis. Se realizaron iteraciones, como es usual en la investigación cualitativa (Sampieri et al, 2014, p. 356), en la medida en que del proceso de la investigación IJESJP, 2018, V6, n1 
emergen nuevas categorías. Se procesaron las entrevistas con auxilio del programa Atlas ti. Luego se hicieron contrastes con las construcciones teóricas y metodológicas pertinentes al tema y, en ocasiones se volvió donde los informantes con nuevas preguntas. En un principio se realizó una revisión bibliográfica detallada acerca del tema central de la investigación con el fin de realizar contrastes respecto a los resultados del análisis de las categorías aplicadas a las entrevistas en profundidad. En ocasiones fue necesario aplicar nuevas categorías y acudir nuevamente al Atlas ti y a la discusión en el grupo de trabajo para elaborar las conclusiones que aquí se presentan. En otras palabras, es una construcción dialógica y compleja y, por ello, refleja la sociedad colombiana, sus territorios y la relación empresarial con los mismos.

Nuestro objetivo s indagar por los aprendizajes personales y concluir sobre los aprendizajes colectivos y de los grupos de pobladores, sin acudir a las metodologías tradicionales de la investigación cuantitativa cuyo aporte es menor cuando se trata de la investigación cualitativa entendida como un "retorno al sujeto", otra expresión utilizada por María Teresa Uribe (Uribe, 2004), y que da cuenta de privilegiar el discurso de sujetos individuales, con “...sus prácticas sociales, sus palabras y discursos, sus memorias y sus olvidos, sus propósitos de cambio, resistencia o sometimiento..." (Galeano, 2004), y buscar allí las lógicas de la actuación personal e institucional. Se acude a la recolección de datos numéricos solamente para precisar el contexto inicial de la investigación. Nuestro objeto es claramente un objeto complejo que no admite la simplificación a estadísticas tradicionales sino que debe ser abordado desde el análisis discursivo, la confrontación de ideas, la particularidad no asible desde una estadística y, quizás también, la incertidumbre sobre los resultados, esto es, la complejidad.

La actuación frente al conflicto armado en Colombia ha sido un asunto de especial interés para muchas empresas, afectadas por el asesinato o secuestro de trabajadores y contratistas, sabotaje contra su infraestructura y sus instalaciones, y, en general, riesgos y consecuencias para el servicio, para su personal y sus familias. Algunas de esas empresas han actuado en conjunto con los GAI, en tanto que otras se han negado a actuar como financiadores de actores armados. No obstante, quieren salvaguardar la vida y la integridad de sus colaboradores. En el último caso, han estructurado su gestión con base en la resistencia frente a los atropellos recibidos por parte de los GAI. El panorama de respuestas, sus modelos y códigos, sus protocolos, criterios y políticas refleja visiones diversas sobre el país y sobre el conflicto, y además, refleja la concepción, usualmente implícita, sobre la sociedad deseada y el rol empresarial en la construcción, respeto y consolidación del Estado de derecho.

Se incluyen testimonios de algunos de los informantes entrevistados con el fin de ilustrar algunas de las afirmaciones que se presentan. En la selección, tanto de los informantes, como de los testimonios extractados, se tiene como criterio definidor el rol del informante en el proceso investigado y la relevancia, para el problema objeto de análisis, de la afirmación que realiza.

\section{HALLAZGOS}

\section{La gravedad del riesgo obligó a revisar las estrategias empresariales}


Cuando el conflicto armado se intensificó, hacia finales del siglo pasado, las amenazas en los territorios se agravaron y esto trajo un riesgo constante para los pobladores que vieron sus derechos humanos violados frecuentemente por todos los actores del conflicto. En cuanto a las empresas, estas vieron en riesgo la viabilidad de sus obras y de sus operaciones debido a la amenaza creciente del conflicto, que afectaba tanto a las empresas industriales como a las empresas que construyen y operan infraestructura en los territorios.

[...] se realizaba una gestión de relación con las comunidades que tenía características muy particulares propias de un aprendizaje y una historia, pero que no correspondía a los grandes cambios en el entorno, especialmente en lo relativo al conflicto [...] El asunto empezó a volverse complicado, entonces hubo un cambio en las personas que hacían la gestión [...] ello significó y facilitó un cambio de modelo. (Informante 1, especialista de gestión social en empresa).

La intensificación del conflicto se caracterizó por una serie de ataques de los GAI, especialmente en el sur del país, que formaban grupos de combatientes con el objetivo de derrotar a las Fuerzas Militares y, dicha intensificación, se reflejó también en el incremento de atentados contra la infraestructura física del país, que afectó de manera especial a sectores como el eléctrico, petrolero, vial, telecomunicaciones, transportes y empresas agropecuarias, pero cuyos efectos tuvieron una fuerte incidencia en todo el país. Al mismo tiempo, los grupos paramilitares crecieron y disputaron el control de territorios de la guerrilla. Esta disputa territorial violenta generó terror en la población debido a los secuestros, asesinatos, retenes ilegales, desplazamientos forzados, desapariciones y masacres, que trajo consigo.

Tanto paramilitares como guerrilleros acudieron a la intimidación y la extorsión como método de financiación y de control territorial, y afectaron también a las empresas localizadas o con actividades en los territorios en disputa. Evidentemente, la guerra tocó con mucha fuerza no solamente a los pobladores, sino también a las empresas. La reacción de las empresas frente al conflicto actúa por varios canales como la incertidumbre y el miedo que se pueden traducir en mayores costos en seguridad, disminuciones en la demanda y necesidad de remplazar personal debido a posibles reducciones en la fuerza de trabajo (Camacho y Rodríguez, 2013, p. 98).

Entre 1958 y 2012 hubo 220.000 personas muertas (CNMH, 2013, p. 20), de los cuales 181.000 eran civiles. De ellos, 150.000 fueron asesinados selectivamente, 1.227 líderes comunitarios y 1.495 militantes políticos, casi todos de izquierda. También fueron secuestrados servidores públicos: 318 alcaldes, 332 concejales, 52 diputados, 54 congresistas y 790 militares y policías. Por otro lado, 27.000 colombianos fueron desaparecidos, 27.023 fueron víctimas del secuestro, en su mayoría extorsivo, y más de 6.000 .000 fueron víctimas de desplazamiento forzado. Además, estos últimos fueron despojados de 8.3 millones de hectáreas y desalojados de 350.000 predios. De igual manera, cabe agregar que 10.000 colombianos fueron víctimas de minas antipersonales, de los cuales 8.000 quedaron lesionados de por vida y 2.000 fallecieron (López, 2016, p. 437). 
Sumado a todo lo anterior, se hizo evidente la falta de fortaleza del Estado para prestar los servicios más básicos, como seguridad y justicia, hecho que, agravado por la corrupción, restringió la posibilidad de encontrar alternativas que permitieran mejoras mínimas a la terrible la situación, así fueran temporales. Otro elemento que hizo aún más compleja la situación fue la lejanía del Estado central frente a las reivindicaciones de las comunidades, originada en la incapacidad de los partidos políticos para tramitar a nivel de políticas estatales las demandas de la protesta social. De ahí que algunos pobladores tuvieran condiciones de vida tan difíciles (Pécaut, 2003, p.20).

En el caso del sector petrolero, por ejemplo, desde 1985 se inició un ciclo masivo de ataques a los oleoductos, especialmente por parte del ELN. Inicialmente fue contra el oleoducto Caño LimónCoveñas, el oleoducto central de Colombia y el oleoducto Trasandino como rechazo a la "entrega del recurso natural a las compañías petroleras extranjeras; además, utilizó los atentados como medio de extorsión contra dichas compañías y logró obtener réditos económicos a través de la extorsión a contratistas" (Villegas, 2016, p.160).

En la siguiente tabla, tomada de varias fuentes y consolidada por los autores, se presenta una estadística de ataques contras diversos tipos de infraestructura, instalaciones públicas y empresas en general.

Tabla 1

Ataques contras infraestructura, instalaciones públicas y empresas.

\begin{tabular}{|l|l|l|}
\hline Numeral & Ataques por objetivo contra el cual se dirigieron & Total \\
\hline 1 & Infraestructura eléctrica (1985-2016) & 2184 \\
\hline 2 & Infraestructura de comunicaciones & 37 \\
\hline 3 & Infraestructura vial y transporte terrestre & 415 \\
\hline 4 & $\begin{array}{l}\text { Infraestructura petrolera (1986-2016) } \\
\text { establecimientos comerciales) }\end{array}$ & 2770 \\
\hline 5 & $\begin{array}{l}\text { Quema de vehículos industrias, entidades bancarias } \\
\text { Qnofincas, empresas, }\end{array}$ & 1401 \\
\hline 6 & $\begin{array}{l}\text { Instituciones públicas (alcaldías, concejos, sedes de la Caja Agraria, sedes } \\
\text { de la Registraduría del Estado Civil, empresas de servicios públicos, entre } \\
\text { otras) }\end{array}$ & 396 \\
\hline 7 &
\end{tabular}




\begin{tabular}{|l|l|l|}
\hline 8 & $\begin{array}{l}\text { Sedes de partidos políticos, organizaciones de derechos humanos, gremios, } \\
\text { sindicatos y organizaciones de la sociedad civil }\end{array}$ & 69 \\
\hline
\end{tabular}

Cerca de 5.000 ataques se dirigieron contra la infraestructura eléctrica y petrolera, de ellos 2.770 contra el sector petrolero entre 1986 y 2016, y 2.184 contra el sector eléctrico. Ambos sectores tienen una historia significativa de gestión social con las comunidades de su entorno y varias de sus empresas habían conformado desde principios de los años noventa equipos de gestión ambiental y social. Sin embargo, la confluencia de la intensificación de la confrontación armada con factores como el período electoral del año 1998, el rechazo a las privatizaciones de empresas, el inicio de conversaciones con las FARC-EP, así como los procesos de discusión de zonas de despeje tanto para FARC-EP como para ELN, hicieron especialmente difícil la situación para las empresas, las cuales se vieron desbordadas por la complejidad de la amenaza y la inexistencia de modelos de gestión que permitieran construir su viabilidad ante la situación de guerra.

[...] Por ejemplo, en 1999, en una reunión, Monseñor Flavio Calle, obispo de la Diócesis Sonsón Rionegro, se dirigió a las empresas del sector ubicadas en el Oriente Antioqueño, estaban ISA, ISAGEN, EPM, estaba además PROANTIOQUIA (Fundación empresarial que agrupa un número muy importante de empresas), y dijo: ustedes llevan muchísimos años en el Oriente, han intervenido el Oriente con su gestión empresarial, pero el Oriente se está desangrando, el conflicto está escalando. ¿Qué vamos a hacer? (Informante 2, especialista de gestión social en empresa).

Se hizo evidente que, en principio, las empresas vieron superadas sus competencias y, como consecuencia, en algunas de ellas se desató un proceso de reflexión sobre el alcance de su gestión $\mathrm{y}$, especialmente, sobre el alcance de los modelos de gestión ambiental desarrollados para el manejo de los impactos, modelos que en muchas ocasiones eran el eje de la relación empresarial con comunidades, pero que, a pesar de los avances logrados en el país partir de la Ley 99 de 1993, solamente se referían a medios veredales y municipales y no alcanzaban con claridad el plano regional. Además, para muchas empresas en su relación con las comunidades primaban criterios de reacción ante reclamos y solicitudes, pero que no daban espacio a la gestión social proactiva. El análisis efectuado identificó situaciones claras de contenido asistencial y escaso alcance regional en sectores como el eléctrico, el petrolero, el minero y algunas empresas industriales. Con dichas metodologías de gestión no era posible enfrentar la amenaza del conflicto.

Lo que vi fue que la empresa se empezó a sacudir cuando la sacudieron los atentados, la muerte de empleados, la muerte de contratistas, las amenazas de muerte a los trabajadores. Con todo esto dijimos ¡Ah! juemadre... ¡es la guerra!, llegó la guerra. Allí se originó un proceso determinante, nos tuvimos que poner a pensar sobre nuestra actuación, sobre la gestión que realizábamos [...] necesitábamos reorientar nuestra actuación. (Informante 2, especialista de gestión social en empresa). 
Tanto en las afirmaciones de informantes en las entrevistas en profundidad como en el análisis de la historia empresarial, especialmente en los sectores más afectados por los ataques, es notorio encontrar cómo la intensificación del conflicto y las amenazas en contra de las empresas las obligaron a reelaborar las estrategias de gestión, inicialmente con las comunidades, aunque algunas empresas llegaron a una comprensión del tema que les permitió concluir que el conflicto no era solamente un asunto con las comunidades en el entorno de los proyectos e instalaciones productivos, sino que era un tema de alcance ciudadano y de interés público, a nivel regional y nacional.

[...] en el comité de riesgo público había discusiones que tenían que ver con asuntos políticos y filosóficos, eran de todo momento, allá no era simplemente discutir sobre llamar o no al ejército. Allá se hablaba de que es un conflicto, que es un derecho internacional humanitario, cuándo aplica, cuáles son las causas estructurales de un conflicto, qué puede esperar la empresa cuando invierte recursos para estos temas, ¿la gestión social es el colchón entre los actores armados y la empresa o sea que la comunidad está en la mitad? Estos temas se analizaban allá, eso no era la discusión de los sociales, era mucho más. Una de las discusiones que aparecía era respecto a la pobreza y su relación con el conflicto, ¿era causa? ¿Era consecuencia? (Informante 1, especialista de gestión social en empresa).

\section{La respuesta de las empresas hizo énfasis, alternativamente, en estrategias de seguridad o en propuestas de viabilidad social}

Al indagar sobre la actuación empresarial en territorios con fuerte presencia del conflicto armado se encuentra contraposición entre enfoque de viabilidad social y el enfoque de seguridad. Este es uno de los grandes temas que se expresa en las diferentes posiciones que manifestaron las empresas, inicialmente, con sus estrategias de gestión social y, posteriormente, en relación con sus estrategias de RSE.

Varias preguntas sintetizan los ejes de los debates realizados con respecto a la actuación frente al conflicto y a los GAI: ¿se trata de acciones para prevenir riesgos únicamente?, ¿se trata de acciones que responden a compromisos éticos y de responsabilidad con la empresa y con la sociedad?, ¿concurre el interés de la empresa de lograr su viabilidad, en medio de situaciones de gran complejidad, con la necesidad de buscar la viabilidad social como condición indispensable de la primera en el mediano y largo plazo? Las respuestas a estas preguntas se dieron en la práctica de las empresas.

La situación de agravamiento del conflicto armado precipitó, en muchas empresas, el enfoque de riesgos, que trata de la seguridad física de personas, recursos y operaciones empresariales. De esta manera, se subordinaron las estrategias de relación con comunidades y de relación con la sociedad en el plano local y regional al manejo de la seguridad y, por lo tanto, se centró fundamentalmente en el corto plazo. Desde este punto de vista, las comunidades en el entorno de la infraestructura se concibieron como grupos sociales manipulados por actores armados ilegales 
o por grupos sociales interesados, los cuales se podían acercar a la empresa mediante inversión de recursos en obras sociales.

Había un deseo de querer hacer algo, de querer mirar el tema. Las discusiones con los jefes de seguridad fueron muy duras, que nos metiéramos en lo que teníamos que hacer. Que había que meter a la gente y que eso era lo que nos iba a salvar un poco, la comunidad se concebía como el colchón. (Informante 2, especialista de gestión social en empresa).

Esta concepción de la comunidad como un factor de riesgo le imprimió a las acciones de inversión social el objetivo de disputar su lealtad, como medio para mejorar las condiciones de manejo del riesgo empresarial. El peso del riesgo impidió ver con claridad las limitaciones de esta actuación que desconocía el hecho de que los GAI amenazaban a la comunidad, quizás, con mayor gravedad que a las empresas.

Una mirada alternativa permite diferenciar comunidades y actores armados y, en la medida en que no se identifican, se pueden realizar acciones de seguridad en conjunto con las fuerzas militares para manejo del riesgo, y acciones con la comunidad para mejorar su calidad de vida, como solidaridad ante la amenaza común. Pero ello le exigía a las empresas una comprensión del conflicto armado en su dimensión política y social, y solo algunas lo lograron.

[...] Por ese entonces nace [...] la visión de que había que afrontar mucho más estructuralmente los temas del desarrollo y no pensar en la gestión social como una medida para administrar riesgos, que era el enfoque que prevalecía en diferentes sectores económicos. De hecho, todavía en algunas empresas se mantiene esa percepción de que las comunidades son guerrilleros de civil o que son simpatizantes o que son la base de los atentados. Entonces, para quienes piensan así, invertir en esas comunidades era como decir: vea, nosotros somos muy queridos no atenten contra nosotros, por el contrario, sean nuestros aliados para evitar los atentados. Lo que se desconocía era la lógica política de los atentados, al final no se realizaban con pretensión de inversión social, sino con la intención de poner en cuestión la capacidad del estado de contrarrestarlos... (Informante 3, especialista de gestión social en empresa).

La respuesta de las empresas partió de la comprensión diferencial del riesgo y adquirió varias posturas que expresaron su interpretación sobre origen del conflicto, sus perspectivas y la posibilidad de buscarle solución como parte del compromiso ético de la empresa. En diferentes medios se han hecho llamados por parte de académicos en el sentido de no hay un actor empresarial unificado frente al conflicto, sino que que existen y existieron diferentes 
acercamientos y posiciones, y por lo tanto diferentes niveles de involucramiento, inclusive de rechazo, hacia los Grupos armados ilegales (GAI).

A continuación, se caracterizan algunas posturas que resumen las respuestas posibles en relación con los GAI, con la fuerza pública y con las comunidades.

\section{- Simpatía}

Es una de las modalidades de actuación empresarial que aparece con mayor claridad en algunas de las empresas que actúan en territorios afectados por el conflicto armado. En esta, la empresa no se resiste a colaborar con los actores armados porque los identifica como un instrumento para conseguir sus propios objetivos empresariales y decide aliarse con ellos.

[...] en Colombia existe suficiente evidencia acerca de la relación de actores corporativos con hechos del conflicto armado interno. Esto tanto sobre la confluencia de intereses económicos (de explotación, producción o distribución) y presencia de actores armados en distintos territorios del país, como sobre la alianza entre poderes económicos, élites locales y grupos armados para promover sus intereses económicos y políticos a través de la cooptación de las instituciones locales en las regiones y a nivel nacional (Dejusticia, 2018, pag 18).

Es una relación simbiótica que parte de identidades ideológicas y de propósitos. Esta modalidad de actuación es bastante antigua en el país. En muchas ocasiones, los marcos de actuación empresarial contienen criterios éticos muy claros. No obstante, dichos criterios son violados por la gerencia de las empresas de manera consciente. En relación con los PDP, en tanto estos están alineados con la comunidad, estas empresas los identifican como un factor de riesgo en el territorio.

\section{- $\quad$ Subordinación}

La empresa accede a colaborar con los actores armados ilegales ante la presión que sufren por parte de estos, la cual juzgan como irresistible. En esta postura la empresa financia actores armados o actúa como cómplice, pero solo como respuesta a la amenaza. Los datos señalan la necesidad de profundizar en una narrativa que distinga entre unos empresarios que fueron víctimas de extorsión ( $13 \%$ de los casos) y otros que voluntariamente financiaron grupos paramilitares para proteger y expandir su actividad económica (86\% de los casos) (Dejusticia, 2018, pag 58).

En esta postura la empresa manifiesta desconfianza ante la capacidad del Estado para evitar las consecuencias de no acceder a la extorsión y se sienten desprotegidas, especialmente si hay la percepción de connivencia entre miembros de la fuerza pública y algún actor armado al margen de la ley. 


\section{- $\quad$ Seguridad}

Es una opción para el manejo del riesgo desde el punto de vista del corto plazo, aunque adolece de un claro análisis que permita identificar la naturaleza de dicho riesgo y, por lo mismo, la existencia de acercamientos diferentes a su manejo. Las empresas se niegan a dar respaldo a los grupos armados que las amenazan de manera violenta y permanente y acuden al marco legal, reclaman la presencia y protección de la fuerza pública y fortalecen sus medidas de seguridad y su marco de actuación con códigos y protocolos definidos para afrontar las amenazas particulares.

[...] entonces yo le dije al empresario: ¿Cuál es el compromiso que tiene la empresa privada en la construcción de paz? y en ese momento me dijo: ninguno, el problema de la paz no es un problema de las empresas, el problema de la seguridad tampoco es un problema de las empresas, yo... el único compromiso que debe tener la empresa es pagar sus impuestos, porque el compromiso de la paz es del gobierno, el gobierno es quien tiene que asegurar un país en paz, ¿sí?, mi deber es pagarle los impuestos para que él haga su tarea, pero la tarea es de él, no mía, ¿sí?, si yo quiero, pues le ayudo (Informante 4, Promotor PDP).

En este enfoque y ante la falta de mayores análisis sobre las características del riesgo, la comunidad se identifica como colaboradora o cercana de los GAI y se intenta conseguir su respaldo mediante la realización de aportes sociales, por lo tanto, la relación con la comunidad y la inversión social se realizan en función de los criterios de seguridad. Lo anterior significa que se concibe que hay cercanía entre los GAI y las comunidades.

\section{- $\quad$ Resistencia}

En esta opción, el manejo de la situación parte de criterios éticos y de responsabilidad con la viabilidad de la sociedad y, simultáneamente, de la empresa y, puede ser caracterizada como intervención sobre el conflicto en la medida en que busca la construcción de paz y actúa sobre las causas del mismo (Prandi, 2010, p. 26). Las empresas realizan procesos de reflexión, en ocasiones colectivos, que les permiten efectuar interpretaciones de mayor profundidad acerca de la naturaleza del conflicto y a partir de allí establecen sus criterios de actuación.

Si, en ocasiones era mucho más analítico, integral, se veía la complejidad de los riesgos un modelo más sofisticado que hacer un convenio con la fuerza pública, para proveer de seguridad. Yo lo que creo es que, era muy difícil con esa herramientas enfrentar esas amenazas, aun con el enfoque de riesgos aunado al uso de herramientas tecnológicas, era muy difícil enfrentar la amenaza del conflicto armado [...] (Informante 5, Promotor PDP).

Al igual que en la opción de Seguridad, las empresas se niegan a dar respaldo a los GAI y acuden al marco legal, reclaman la presencia y protección de la fuerza pública y fortalecen su marco de 
actuación, pero a diferencia de la opción de seguridad, concluyen que la viabilidad de la sociedad, expresada en los territorios en los cuales actúan, es una apuesta de largo plazo que igualmente tiene réditos en viabilidad empresarial, pero que asumir el largo plazo requiere una reflexión sobre la construcción de la paz como un objetivo prioritario.

En su relación con la comunidad, diferencian a esta de los GAI y reconocen que los pobladores actúan presionados y amenazados por dichos grupos, tanto como ellas, y, por la misma razón, no los identifican con los GAI, aunque en algunos casos pueda existir cercanía entre ellos y la comunidad. Además, realizan inversión social con el objetivo de contribuir a la mejora de la calidad de vida y de la situación crítica generada por el conflicto. En esta opción, las empresas respaldan los Programa de Desarrollo y Paz y contribuyen a la búsqueda de mejores condiciones de vida aún en medio del conflicto.

Entonces, los PDP tienen un papel muy importante, porque son el único factor de confianza en los territorios, entre otras cosas por la presencia de la iglesia. La llegada de las empresas le da una perspectiva empresarial. Para ese entonces los conflictos con las empresas no están en el primer plano en todas las regiones, en este está, la atención humanitaria, aceptación, acompañamiento, observación, y las empresas le dan un cierto respaldo institucional a unas comunidades que estaban siendo muy vulneradas. La lógica era quitarle el agua al pez, porque se estaban desplazando masivamente comunidades y matando líderes comunitarios y eso destruía el tejido social (Informante 5, Promotor PDP).

En Colombia, en el año 1995, previo a un diagnóstico participativo, se creó el Programa de Desarrollo y Paz del Magdalena Medio, facilitado, a su vez, por un consorcio en el cual participaron la Diócesis de Barrancabermeja, el Bienvenidos al Centro de Investigación y Educación Popular (CINEP) y la Sociedad de Amigos del País, con el financiamiento de la empresa Ecopetrol y de fondos comprometidos en la firma de la convención colectiva de ese año (De Roux, 1999, p. 8). Posteriormente, se crearon los Programas de Desarrollo y Paz (PDP) en territorios afectados por la intensidad del conflicto. A la mayoría de ellos se han vinculado empresas. En territorios donde no existen estos programas, algunas empresas realizan procesos de diálogo respetuoso con las comunidades en búsqueda de acuerdos sobre el desarrollo de las actividades empresariales.

\section{En las respuestas empresariales se hicieron explícitos criterios de RSE}

Si se analiza la actuación empresarial bajo la postura de resistencia se encuentra que los planteamientos de la ciudadanía corporativa permiten una aproximación al asunto. El énfasis se concentra en un comportamiento ético más allá de las obligaciones legales y en evitar que se comprometan las normas éticas para alcanzar los objetivos empresariales y reconocer que la integridad empresarial y el comportamiento ético van más allá del mero cumplimiento de las leyes 
y reglamentos (Carrol, 2016, p. 3). La ciudadanía corporativa "supone, más que un cambio en las prácticas de gestión, un cambio en la forma de entender el rol de la empresa en la sociedad.

A las empresas nos pueden ver como los agentes del conflicto por las tensiones, por el desarrollo que han generado en los territorios, eso nos coloca en la otra orilla, o sea que nos identifican como los que han promovido conflictos en los territorios. Nos acusan de haber agenciado un modelo de desarrollo que no es del territorio. Entonces concluimos que si queremos ser viables en esos territorios, tenemos que cambiar el enfoque de cómo hacemos desarrollo (Informante 3, especialista de gestión social en empresa).

Las empresas ciudadanas integran la RSE en su gestión estratégica" (Castelló \& Lozano, 2009, p. 25). Lo anterior significa que las empresas cambian sus marcos de actuación, definen políticas y protocolos y reconocen la gravedad de la situación y la necesidad de actuar en conjunto con otros actores regionales para intentar construir alternativas de respeto a los derechos humanos en medio de la confrontación. Este fue un período, a partir del final de los años noventa, en el cual, las acciones de RSE alcanzaron reconocimiento $\mathrm{y}$, conceptos y prácticas como teoría de grupos de interés, ética empresarial y ciudadanía corporativa, se articularon a la gestión empresarial (Masoud, 2017, p. 5). En el caso colombiano, al tiempo, se desarrollaron programas de capacitación para que los empleados comprendieran el riesgo y adoptaran medidas de protección personal y de las instalaciones.

Los PDP pretenden desatar una dinámica de construcción de paz y desarrollo en territorios en guerra. Además, expresan una búsqueda de viabilidad social a través del aporte y el apoyo a procesos de construcción de paz en medio del conflicto en entornos cuya complejidad es mayor debido a la presencia de otros factores como la baja calidad de vida de comunidades, organizaciones sociales débiles, atemorizadas o cooptadas, presencia de narcotráfico, instituciones estatales locales débiles o cooptadas por actores al margen de la ley o por caciques que usufructúan el Estado. El objetivo de los PDP es la vida digna con plenitud de derechos humanos de todos los pobladores de la región mediante la convivencia ciudadana en una cultura de la paz que ponga las bases para la construcción del espacio de lo público o construcción del hogar común, de donde nadie sea excluido; y la puesta en marcha de una economía sostenible desarrollada y controlada por pobladores, organizaciones, campesinos y empresarios locales, que ponga la calidad de vida regional como primer objetivo de la actividad productiva regional, y por un Estado y una sociedad que forjen el capital social y natural indispensable para la convivencia y las iniciativas de las personas y los grupos. (De Roux, 1999, p. 20)

Los PDP actúan como facilitadores del empoderamiento de las comunidades. La noción de empoderamiento remite a la decisión de autodeterminación individual y colectiva sobre la participación democrática en la vida de la comunidad, y en la propia vida (Rapaport, 1987, p. 121). Parten también de retomar planteamientos como la propuesta de "agencia del individuo" (Sen, 
2000 , p. 35), la cual puede entenderse como la capacidad de los individuos de hacer uso de las libertades para pensar y para prever qué se espera del desarrollo y qué se valora como calidad de vida, y gestionar de acuerdo a ello. En otras palabras, es la capacidad de los individuos de comportarse como agentes activos de cambio y no como receptores pasivos de prestaciones; es el elemento que permite que se conecten las oportunidades que crean las instituciones de seguridad social, el sistema democrático y el sistema económico en la parte del mercado; es la capacidad de los individuos para configurar su propio destino y ayudarse mutuamente, no siendo agentes pasivos del desarrollo ni agentes pasivos de programas de desarrollo, por muy metódicos, elaborados y por muy sistemáticos que ellos sean (Sen, 2000, p. 21).

Algunas empresas se vincularon a los PDP como gestores, miembros plenos y aportantes; participaron en juntas directivas, en algunos casos, $y$, en otros, como participantes, respaldando el funcionamiento del ente gestor del programa, pero sin ser miembro de junta directiva. Otro nivel de participación fue la vinculación a la Red Nacional de Programas de Desarrollo y Paz como entidad de apoyo, aún sin participar en ningún programa en particular.

\section{CONCLUSIONES}

De las consideraciones efectuadas se puede concluir que la actuación empresarial en territorios en conflicto está determinada por la búsqueda de viabilidad de las obras y ello se ubica en el campo de la relación empresa-sociedad, pues la ni empresa, ni sus obras y proyectos están separados de la sociedad. Los PDP facilitaron, en tanto mecanismos colaborativos entre diferentes actores (Austin, 2000, p. 73), algunos de ellos empresariales, la mejora de la capacidad colectiva de resolver problemas, esto es, el empoderamiento comunitario, individual y colectivo (Trujillo, 2014, p. 6). En ocasiones la empresa actúa frente a presiones externas del ámbito político que actúan como motivación a comportamientos, esto es la conexión política (Huang y Zhao, 2016, p. 7). Se evidencia que Existen objetivos de orden social que están en la base de la organización empresarial y que la justifican como institución. Además, existen criterios éticos de comportamiento en tanto institución social que también aplican a las empresas para lograr y mantener la legitimidad de su actuación (Raufflet et al, 2012, p. 20), en contextos particulares. Por otro lado, es precisamente la existencia de esos riesgos y retos lo que muchas veces lleva a las empresas a trabajar en iniciativas innovadoras de cara a la superación del conflicto apostando por la construcción de paz y el respeto a los derechos humanos. Para quienes viven en Colombia, la definición de un entorno complejo puede parecer familiar en tanto los factores que lo caracterizan confluyen en muchas regiones del país (Prandi y Lozano, 2010, p. 104).

La construcción de un país en paz es un interés de la sociedad y, por lo tanto, es un interés de las empresas que operan obras de ingeniería en los territorios afectados por el conflicto armado. Efectivamente, la empresa deberá diseñar una gestión para adecuarse a las características políticas, ambientales y culturales de la población y las instituciones en dichos territorios y así avanzar en su viabilidad, aunque los réditos solo se puedan vislumbrar en el mediano y largo plazo. De igual manera, en la construcción de paz, la empresa tiene un lugar que, en principio, parte de su experiencia y de sus aprendizajes en medio del conflicto. 
La ciudadanía corporativa, como estrategia empresarial, es un énfasis posible de la RSE y una propuesta ética de largo plazo que respeta los procesos sociales sobre los que la empresa no tiene control, pero sí interés. Por lo tanto, permite contribuir de mejor manera a las acciones adelantadas por las empresas en territorios de conflicto armado. En tanto la solución del conflicto armado es interés también de las empresas, estas deberán diseñar su gestión para adecuarse a las características políticas, ambientales y culturales de la población y las instituciones en esos territorios para poder avanzar en su viabilidad. La empresa ciudadana es "aquella que incorpora plenamente los principios de la sostenibilidad humana y ecológica en sus propias operaciones y que, asimismo, trabaja activamente para apoyar la aplicación de los principios de la sostenibilidad en el resto de la sociedad" (Castelló \& Lozano, 1999, p: 27). Lo anterior supone que la responsabilidad de la empresa tiene, a la vez, una dimensión económica, social y ambiental, dimensiones inherentes a las relaciones con los diversos grupos de interés y que, más que un cambio en las prácticas de gestión, supone un cambio en la forma de entender el rol de la empresa en la sociedad.

El hecho implícito en las transformaciones empresariales fue el reconocimiento de que la empresa tenía un rol como actor regional y que ese rol podía ser la contribución a construir, en conjunto con otros actores regionales, escenarios de superación del conflicto. Esos escenarios los proporcionaron los PDP precisamente, programas que pueden ser entendidos como una confluencia de actores territoriales que deciden trabajar juntos para explorar nuevos caminos en búsqueda de la paz en las regiones y que hacen un llamado a los pobladores a participar desde la base; a partir de allí, formulan su visión territorial y ponen en marcha proyectos en temas como paz y derechos humanos, tierra y ordenamiento territorial, educación, desarrollo humano integral y sostenible y gobernabilidad democrática.

La operación de los proyectos de desarrollo, proyectos con un gran contenido de ingeniería, no puede aislarse de los procesos de apropiación del territorio por parte de los pobladores y sus regiones, ya que ellos inciden de manera definitiva en la estructura y la gestión empresarial.

Efectivamente las empresas han sido parte en el conflicto y me parece interesante que ustedes se pregunten cómo pueden ser parte en la paz, porque si usted no es parte de la solución usted es parte del problema y hoy decimos que si usted es parte del problema debe ser parte de la solución; una cosa que veo hacia el futuro y me parece importante es que las empresas tengan un cambio de chip y es comprender que cuando uno llega a una región se vincula a un proceso regional de producción de valor y que uno no llega a extraer el valor de ese territorio sino a acrecentar el valor que se hace en la región; el principal valor de la región son los seres humanos, lo cual incorpora inmediatamente a la cultura, a la tradición, a la educación y a la memoria de las víctimas...eso es muy importante (Informante 6, Promotor PDP).

De igual manera, la presencia en un territorio en conflicto, más allá de las consideraciones de productividad, es la oportunidad para una empresa fundamentada en criterios de ética y de 
responsabilidad de aportar en la solución a los problemas de interés público, a medida que fortalece su legitimidad y le permite acumular fuerzas para el mediano plazo, pero ello sólo es posible con un entendimiento profundo del contexto (Tilt, 2016, p. 8) y una respuesta ética frente a él, esto es una perspectiva de sensibilidad al conflicto. En efecto, no es solo una apuesta económica sino una apuesta ética.

Para que la empresa contribuya a la paz es vital que esta adopte lo que se ha llamado en el argot humanitario una perspectiva de "sensibilidad al conflicto". Esta significa que, partiendo del análisis del conflicto, la empresa debería comprender y anticipar su interacción con el contexto evitando los impactos negativos y maximizando los positivos en el proceso de construcción de paz. (Prandi y Lozano, 2010, p. 29).

La elaboración de la reflexión sobre el rol empresarial en medio del conflicto y las conclusiones que de allí se desprenden hacia el futuro son necesarias para el país debido a las transformaciones sociales y políticas que se viven en la actualidad y que se vivirán en las próximas décadas. Los retos que se enfrentan en el proceso de construcción de paz en las regiones es el espacio en el cual la actuación empresarial puede contribuir a construir la paz o, por contrario, contribuir a que no sea posible. En todo caso la empresa debe partir de reconocer su rol como actor en el conflicto armado, y el significado de la presencia de sus obras en los territorios, para actuar de manera consciente, ética y responsable como actor en la construcción de paz. Es un nuevo punto de partida, un proceso en el cual el aporte de los Programas de Desarrollo y Paz es fundamental debido a su vínculo social en los territorios y porque su objetivo es exactamente ese: la construcción de paz a través del empoderamiento de los pobladores sobre las decisiones de su propia calidad de vida en el plano regional.

[...] los Programas de Desarrollo y Paz invirtieron la lógica de construcción del Estado, ya no es construir el Estado desde el territorio sino llevar el territorio al Estado, y eso es lo que significa un PDP, es un nuevo pacto social, político y económico. Eso debería ser un PDP en su fase plena de maduración y Sergio Jaramillo dice: la enfermedad histórica de Colombia ha sido la fragmentación social [...] los programas de desarrollo con enfoque territorial van a ser en la práctica unos nuevos acuerdos políticos en los territorios, que van a establecer las nuevas reglas de fuego, porque al final este proceso de paz está pensado en esa lógica $[. .$.$] y en eso no se parece a ninguno de los procesos que hemos vivido. Entonces$ la contribución de los empresarios probablemente no será generar empleo, sino pensar como los encadenamientos productivos logran articularse con las economías regionales que van a florecer (Informante 6, Promotor PDP).

Sin embargo, los pobladores requieren estar dotados de los servicios del Estado. Para ello es indispensable remover las restricciones que les impiden gestionar su propia agencia y poder buscar IJESJP, 2018, V6, n1 
y lograr la calidad de vida deseada. En el contexto colombiano se requirió una reflexión sobre el conflicto armado para lograr su comprensión como un hecho político y, con ello, diseñar estrategias que le permitiera a las empresas avanzar en la búsqueda de una solución ya que allí estaba involucrada también la viabilidad social, la calidad de vida de los pobladores de las regiones y la viabilidad de la operación empresarial.

Finalmente, este texto hace énfasis en diferentes empresas, propietarias de proyectos de infraestructura para la prestación de servicios que han sido llamadas obras de ingeniería, se han vinculado a la promoción y apoyo a los Programas de Desarrollo y paz, verdaderos proyectos colaborativos construidos en conjunto con un espectro amplio de interlocutores tales como empresas, iglesias, gremios, universidades y organizaciones sociales locales y regionales, todo ello con el objetivo de articular, sobre el territorio, las obras de ingeniería con procesos de respeto a los derechos humanos y mejora en la calidad de vida en medio del conflicto armado. El resultado de dicha confluencia, es la construcción de procesos complejos a nivel territorial en los cuales las empresas propietarias de obras de infraestructura despliegan acciones y metodologías de planeación y gestión, diseñadas por grupos de profesionales de las diferentes ciencias naturales y sociales, valga decir ambientales, que logran diferentes niveles de articulación con los abundantes equipos de ingenieros que, tradicionalmente, conformaban las empresas. Es un proceso de reconocimiento de las obras como sistemas sociales, complejos, a los cuales convergen disciplinas y conocimientos, más allá de la ingeniería, pero en los cuales la ingeniería tiene un rol determinante.

\section{REFERENCIAS}

Austin, J. (2000). Strategic collaboration betwen nonprofits and business. Journal of Nonprofit and voluntary sector quarterly, 69 - 97. DOI: https://doi.org/10.1177/0899764000291S004

Camacho, A. \& Rodriguez, C. (2013). Firm Exit and Armed Conflict in Colombia. The Journal of Conflict Resolution, Vol. 57, No. 1, Special Issue: Entrepreneurship and Conflict, 89-116. DOI: https://doi.org/10.1177/0022002712464848

Carroll, A. (2016). Carroll's pyramid of CSR: taking another look. International Journal of Corporate Social Responsibility, 1-8. DOI: 10.1186 / s40991-016-0004-6

Castelló, I., \& Lozano, J. (2009). De la gestión del riesgo a la empresa ciudadana: los estadios de evolución de la $\quad$ RSE. Obtenido de: http://www.academia.edu/878610/De_la_gesti\%C3\%B3n_del_riesgo_a_la_empresa_ciudadana_1 os_estadios_de_evoluci\%C3\%B3n_de_la_RSE

Centro Nacional de Memoria Histórica. (2013). ¡Basta ya! Colombia, memorias de guerra y dignidad. Obtenido de: http://www.centrodememoriahistorica.gov.co/descargas/informes2013/bastaYa/basta-yamemorias-guerra-dignidad-new-9-agosto.pdf 
De Roux, F. (1999). El Magdalena Medio en el centro de conflicto y de la esperanza. Revista Controversia, 174, p. 153.

Galeano, M. (2004). Estrategias de investigación social cualitativa. El giro en la mirada. Medellín: Editorial Lealón.

Huang, H., \& Zhao, Z. (2016). The influence of political connection on corporate social responsibility_evidence from Listed private companies in China. International Journal of Corporate Social Responsibility, 1 - 19. DOI 10.1186 / s40991-016-0007-3

López, C. (2016). ¡Adiós a las FARC! ¿Y ahora qué? Construir ciudadanía, Estado y mercado para unir las tres Colombias. Bogotá: Penguin Random House.

Masoud, N. (2017). How to win the battle of ideas in corporate social responsibility: the International Pyramid Model of CSR. International Journal of Corporate Social Responsibility, 122. DOI: $10.1186 / \mathrm{s} 40991-017-0015-\mathrm{y}$

Pécault, D. (2003). Midiendo fuerzas: balance del primer año del gobierno de Álvaro Uribe Vélez. Bogotá: Editorial Planeta.

Prandi, M., \& Lozano, J. (Eds.). (2010). La RSE en contextos de conflicto y posconflicto: de la gestión del riesgo a la creación de valor. España: Escola de Cultura de Pau (UAB)/ Instituto de Innovación Social (ESADE).

Prandi, M. (2010). De los conflictos armados a la construcción de paz. España: Escola de Cultura de Pau (UAB)/ Instituto de Innovación Social (ESADE).

Rappaport, J. (1987). Terms of Empowerment/Exemplars of Prevention: Toward a Theory for Community Psychology. American Journal of Community Psychology, 121-147. DOI: 10.1007/BF00919275

Raufflet, E., Lozano, J., Barrera, E., \& García, C. (2012). Responsabilidad social empresarial. México: Editorial Pearson.

Sampieri, R, Fernández, C, Baptista, P. (2014). Metodología de la investigación. McGRAW-HILL / INTERAMERICANA EDITORES, S.A. DE C.V. México D.F.

Sánchez, Nelson, Leigh Payne, Gabriel Pereira, Laura Bernal, Daniel Marín, Miguel Barboza, "Cuentas Claras", El Papel de la comisión de la Verdad en la Develación de la Responsabilidad de Empresas en el Conflicto Armado Colombiano, (Bogotá, Dejusticia, 2018).

Sen, A. (2000). Desarrollo y libertad. Santa fe de Bogotá: Planeta Colombiana Editorial S.A.

Tilt, C. (2016). Corporate social responsibility research: the importance of context. International Journal of Corporate Social Responsibility, 1 - 9. 10.1186 / s40991-016-0003-7

Trujillo, D. (2012). Value creation in cross-sector collaborations and the nature of public value [tesis doctoral]. NYU Wagner School of Public Service, University of Los Andes, Bogotá.

Uribe, M. (1998). Las soberanías en vilo en un contexto de guerra y paz. Revista Estudios Políticos No. 13. Universidad de Antioquia, Medellín. 
Villegas y Delgado

Proyectos de ingeniería y conflicto armado: Una perspectiva de RSE

Villegas Rodríguez, L. (2016). Infraestructura, medio ambiente y protesta social. Medellín: Sello Editorial Universidad de Medellín. 